
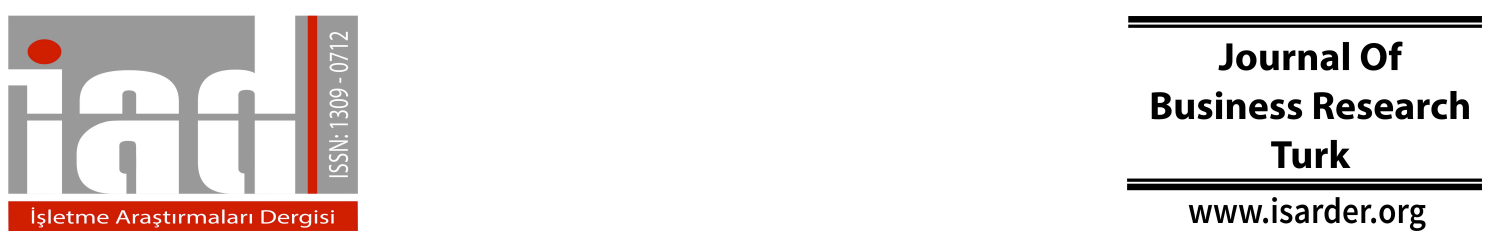

\title{
Examination of Urban Hotels' Online Review Site Performance with a Comparative Approach based on TripAdvisor and Booking
}

\author{
Ramazan Ufuk BAYER \\ Anadolu University, Institute of Social \\ Sciences, Eskisehir, Turkey \\ orcid.org/0000-0003-4391-1384 \\ r.ufukbayer@gmail.com
}

\author{
Oktay EMíR ${ }^{1}$ \\ Anadolu University, Faculty of Business \\ Administration, Eskisehir, Turkey \\ orcid.org/0000-0002-7972-1980 \\ oktayemir@anadolu.edu.tr
}

\begin{abstract}
It is an indisputable fact that social media technology has been changing the way of consumers' information production and knowledge acquisition patterns in terms of their consumptions. One of the most essential components of social media is customer reviews. In tourism field, there are different types of hotel review sites. The purpose of this research is to examine the hotels' online review performance in the top two review sites (Booking and TripAdvisor) comparatively. The data were collected electronically from the two review sites about 82 hotels located in Ankara and 59 hotels located in Izmir. These total 141 hotels were selected randomly among the ones which are mutually listed in both Booking and TripAdvisor. The findings show that there is a statistically significant difference between TripAdvisor and booking based on the number of hotel reviews and most of the review take place on Booking. Besides, it is revealed that big-scale hotels are better at managing online review sites rather than the small and mid-scale hotels. Another interesting result of this research is that hotel guests dominantly share reviews for showing their satisfaction rather than their dissatisfaction. In accordance with the results obtained from the research, some suggestions are made for researchers and hotel marketers.
\end{abstract}

Keywords: Social Media, Online Travel Agency Website, User-generated Content, Online Hotel Reviews, Ankara, Izmir.

\section{Introduction}

The world is increasingly digitalized and it is a well-known fact that this digitalization profoundly affects the marketing. Digitalization shows itself almost in all markets and changes the consumer behaviors overwhelmingly. As technological revolution has been affecting most of the industries, it has been affecting the hospitality industry in the same manner. Buhalis and Law (2008) asserted that especially the distribution system of the hospitality field is dominated by the online channels because tourists prefer to make their hotel reservations via online channels. Unfortunately, websites which enable tourists to make their reservations online are mostly static in

\footnotetext{
${ }^{1}$ Corresponding Author
} 
previous years (Chan and Guillet, 2011) and it was not the one that tourists desire. This problem was recognized and corrected through the development of social media channels in the following years. The dawn of social media has a substantial place in the historical development of internet. It is accepted that there is two turning points in the development of internet technology; the first of them is the search engine and the second one is the social media (Xiang and Gretzel, 2010; Leung et al., 2013).

Social media has enhanced the statues of the internet users from passive to active (Yacouel and Fleischer, 2012; Cantallops and Salvi, 2014). The internet users could just read the content in the websites that are developed by web 1.0 technology. Fortunately, they can both read and generate content with the foundation of web 2.0 technology. Social media is the top of the agenda for many business executives (Kaplan and Haenlein, 2010) because consumers can share their opinions, ideas, expectations, experiences in social media and contribute to the enrichment of the online content through their sharing (Litvin, Goldsmith and Pan, 2008; Kaplan and Haenlein, 2010; Leung, et al.; 2013; Xie, Chen and Wu, 2016). In a sense, customers have a new communication channel in which their voices can be heard by all the stakeholders of the organizations. Furthermore, there isn't any censorship within social media. In other words, the information on the internet is not under the control of the supply side as it was in the past. Beyond these, tourists generate content without any commercial concern (Buhalis and Law, 2008). These make the content created by customers much more valuable than the other sources for the potential consumers (Bronner and Hoog, 2011).

Prospective tourists consult to the consumer-generated content by means of social media channels and their travel-related decisions are deeply affected by other tourists' opinions (Gretzel and Yoo, 2008; Yoo and Gretzel, 2012; Liu et al., 2013) because they regard themselves as peers. According to PhocusWright (2008), more than $80 \%$ of the tourists made their travel decisions under the influence of contents (videos, blogs, tweets, reviews etc.) generated by other tourists. There are different types of usergenerated contents like photos, videos, blogs, tweets, reviews etc. In fact, the most influential and popular type of content is the online reviews for the hospitality and tourism field (Schuckert, Liu and Law, 2015). There is a recent research study which revealed that $49 \%$ of potential tourists won't make their hotel reservations without reading online tourists reviews (Statisticbrain, 2014). According to another one, threequarters of the tourists make their travel-related decisions considering the online reviews which are shared by other tourists (Xie, Zhang and Zhang, 2014). These figures are some statistical evidences pointing out how crucial the issue is.

Online reviews do not only help the tourists but also offers hospitality managements to gain competitive advantage and customers' loyalty through interacting with their customers, understanding tourists' expectations, recovering service failures, improving their services (Chan and Guillet, 2011; Munzel and Kunz, 2014; Schuckert, Liu and Law, 2015). It is obvious that online review is a valuable information type for both tourists and hospitality managements. However, neither industry practitioners nor researchers work out well about this matter. As it is pointed out by some researchers (Chan and Guillet, 2011; Leung, et al., 2013), practitioners do not show successful performance within the channels where hotel reviews are published by tourists. At the same time, this issue is required to be investigated in-depth by the researchers because there are lots of things remaining as unknown in terms of the theory (Gretzel and Yoo, 
2008; Leung et al., 2013). In this research, the top two websites (TripAdvisor and Booking) containing tourists' reviews on hotels are investigated through adopting a comparative approach. Cantallops and Salvi (2014) draw attention specifically to the necessity of the studies investigating the variables associated with the number of hotel reviews. The aim of this research is to uncover;

- The platform on which tourists prefer to share their hotel reviews more,

- Whether the hotel class is an important parameter on the number of reviews or not,

-Whether more hotel reviews mean better virtual impression for hotels,

- Whether the success indexes of the hotels in different platforms are consistent with each other or not.

Hotel managements have the chance to reach the scientific information which guides them about the variables related with the total number of reviews shared towards their establishments and concentrating to which platforms more through the result of this research. This research does not only aim to lead the way for the hospitality practitioners but also contribute to the body of knowledge about online review issue. It can be said that those are the arguments making this research important. The research is composed of four parts (literature review, methodology, results and discussion) taking place in the following parts.

\section{Literature Review}

Social media can be defined as the internet-based applications which are constructed on web 2.0 technology and enables internet users to share their ideas, thoughts, experiences, opinions and to interact with others (Chan and Guillet, 2011). Also, social media is simply the online media where the contents can be generated by the users of the internet (Xiang and Gretzel, 2010). It is possible to come across with different social media definitions and the synonyms of it in the literature. There are different notions like social website, user-generated content (UGC), user-created content (UCC), consumer-generated media (CGM), online reviews, online recommendations, word-of-mouse and Web 2.0 which are used instead of social media (Stringam and Gerdes, 2010; Chan and Guillet, 2011; Filieri and McLeay, 2013; Cantallops and Salvi, 2014). Although most of these notions have the similar meanings in a broad sense, some researchers have differentiated them distinctively. For instance, Kaplan and Haenlein (2010) draw attention to the difference of three concepts (web 2.0, user-generated content and social media). Similar to that fact, there are lots of different media types which are used by tourists and content types created by them. It is concentrated on just two of the online hotel review including social media sites Booking and TripAdvisor in this research.

Proliferation of social media has collapsed the monopoly in terms of the information production on the internet and digital environment becomes increasingly more democratic. Tourists can read the information produced by the hospitality firms and also by the other tourists with the advent of social media sites. Furthermore, they can generate content about their experiences through social media. In sum, tourists' experiences are getting increasingly transparent in consequence of tourists' shares about their experiences within this new framework of the internet. Tourists share contents about their experiences voluntarily and without any commercial purpose (Schuckert, 
Liu and Law, 2015). Potential tourists can access these unbiased and uncensored contents which are generated by other tourists (Jeong and Jeon, 2008). These details make tourist-generated contents valuable for potential tourists and they perceive that tourist-generated content is more precious and trustful than the information produced by the hospitality firms (Melián-González et al., 2013).

It is known that consumers attach more importance to online reviews when they are searching information about services rather than physical products. Some characteristics (intangibility, complexity and experiential nature) of tourism product/services likewise all other services intrinsically make online reviews centered on the focal point of contemporary issue (Bansal and Voyer, 2000; Chung and Buhalis, 2008; O'Connor, 2008; Litvin and Hoffman, 2012). In addition to these, purchasing tourism products and services is a kind of high involvement purchase and is perceived as highly risky (Park, Kim and Han, 2007; Litvin and Hoffman, 2012). Touristsgenerated contents decrease potential tourists' perceived risk level and its uncertainty. Normally, tourism products/services can be evaluated after purchase and experience. However, potential tourists gain insight about their potential experiences, in other words, indirect experience through reviewing the contents shared by other tourists (Bickart and Schindler, 2001; Xie, Chen and $\mathrm{Wu}$; 2016). Apart from these advantageous of online reviews for tourists, these contents reduce tourists' costs (time, effort etc.), enhances the quality of choice (Bronner and Hoog, 2011) and post-purchase dissonance (Litvin, Goldsmith and Pan, 2008). Furthermore, Chatterjee (2001) stated that potential consumers give more importance to the other consumers' reviews when a consumer is unfamiliar with a service provider which is often the case for tourism-related decisions.

Tourists can share contents about their travel experiences in different channels and also new ones continue to be added to this channel list. There are some researchers examined which of these have a more important place among the social media channels in the tourism field. Xiang and Gretzel (2010) searched the identified keywords about some of the tourism destinations and they found out that search engines direct travelers to social media sites when they are doing searches about travel product/services. Also, these social media sites are classified and it is calculated the percent of the search results belonging to which type of social media. According to their research results; $40 \%$ of the social media sites are virtual communities (igougo.com, lonelyplanet.com etc.) and $27 \%$ of them are review sites (zagat.com, tripadvisor.com etc.). Although most of the researchers don't accept online travel agency sites (OTAs') as a social media sites, it is well-known fact that tourists can share content in OTAs' as well. However, there isn't any scientific information about whether online hotel reviews are more commonly shared in online review sites or online travel agencies sites.

In the literature, some of the most popular issues can be listed as the profiling the online review publishers, readers and understanding their motivation of contentcreations (Gretzel and Yoo, 2008; Bronner and Hoog, 2011; Yoo and Gretzel, 2012). According to these research results; tourists sharing information about their travel experiences are generally single, young, male, employed full-time, have higher incomes and greater internet skills, highly involved in trip planning. Although there are many researchers investigated the online hotel review publishers' demographic characteristics, it is a remarkable point that just a few researchers examine the relationship between the total number of hotel reviews and the characteristics of hotels. Ögüt and Cezar (2012) identified the variables which affect the total number of reviews made about the hotels 
located in Paris and they found that lower price increases the propensity to write reviews. Also, they have found the evidence for the negative effect of larger room size on the propensity to write a review. (Öğ̈̈t and Cezar, 2012).

There isn't any hesitation about the popularity of online hotel reviews. Although tourists' tendency to read and publish hotel reviews continue to rise, hospitality businesses have negative attitudes towards these review platforms because they think that tourists usually share reviews when they have problems with their enterprises. Hospitality managements would like to have just the positive reviews and avert from the negative ones. If they want to have a better image, they have to strive to find the ways of increasing the reviews made about their establishments. Melián-González et al. (2013) indicated that the review valence becomes more balanced when the number of reviews increases and the effect of negative reviews is mitigated. Furthermore, they unearth that positive reviews are more common than negative ones. This is supported by Ögüt and Cezar (2012) and they came up with the result that satisfied tourists are more willing to write reviews than the dissatisfied tourists.

\section{Methodology}

There are three sub-headings under the main heading of methodology. First, all the research hypotheses are provided in this part. Then, sampling and data collection is explained elaborately. Lastly, all the analysis that are conducted while testing the hypothesis of this study are indicated.

\subsection{Research Hypotheses}

In this research study, seven main hypotheses are developed for the purposes of the research and based on the literature review. There is a necessity of developing five sub-hypotheses for the fifth one, and four sub-hypotheses for the sixth. In sum, there are total fourteen hypotheses to be tested and these are listed below.

$\mathbf{H}_{1}$ : There is a statistically significant difference in the number of reviews between TripAdvisor and Booking for the same hotels.

$\mathbf{H}_{2}$ : There is a statistically significant difference in total number of hotel reviews based on the hotel categories.

$\mathbf{H}_{3}$ : There is a statistically significant correlation between total number of hotel reviews and hotels' number of rooms.

$\mathbf{H}_{4}$ : There is a statistically significant correlation between total number of hotel reviews and average room rates of hotels.

$\mathbf{H}_{5 \mathrm{a}-5 \mathrm{e}}$ : There is a statistically significant correlation between total number of hotel reviews and number of hotel reviews scored with 1 to 5 .

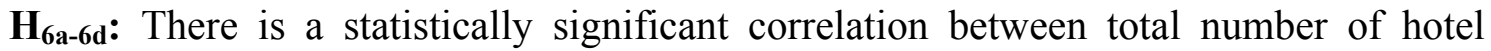
reviews, ranking and overall score of the hotels in Booking and TripAdvisor.

$\mathbf{H}_{7}$ : There is a statistically significant difference in ranking of the same hotels between TripAdvisor and Booking. 


\subsection{Sampling and Data Collection}

The research population is composed of all urban hotel establishments in Ankara and Izmir. In this study, the aim is to collect the data about the hotels located in the biggest top three cities (Istanbul, Ankara and Izmir) in Turkey from two review sites. It is thought that Istanbul shouldn't be in the population of this research because it doesn't show the same patterns alike the other cities and takes place in the list of world class tourism destinations. For this reason, the data on the urban hotels located in Ankara which is the capital city of Turkey and in Izmir - one of the most visited destination of Aegean region is collected from the specified two review sites within the scope of this study.

When a hotel search is done without any filter in either Booking or TripAdvisor, the result page includes the all types of accommodation enterprises. In fact, the type of the accommodation enterprises is limited with the 5, 4, 3 star and boutique hotels in this research. For this reason, all the searches are done based on the previously mentioned hotel class filtration. There are 104 hotels listed in the TripAdvisor's hospitality enterprises result page for Ankara. On the other hand, there are 112 hotels listed when a search is performed for Ankara on Booking. However, there are just 91 hotels located in Ankara which are mutually listed in TripAdvisor and Booking. According to sample size calculation in the $95 \%$ confidence level, these 91 hotels can be represented with observing at least 74 of them. In this research, 82 hotels located in Ankara which are mutually listed in TripAdvisor and Booking are selected randomly in the sample. Also, the same procedure is applied for the hotels located in Izmir. There are 62 hotels located in Izmir which are mutually listed in both two review sites. Minimum sample size is calculated within the $95 \%$ confidence level and at least 59 hotels should be observed in order to represent the population. Fifty-nine hotels located in Izmir which are mutually listed in aforementioned review sites are selected randomly. Consequently, the data related with a total of 141 hotel establishments in both Booking and TripAdvisor are collected manually. The profile of the hotels is presented in the Table 1.

Table 1. Sample Profile

\begin{tabular}{|c|c|c|c|c|c|c|c|c|c|c|}
\hline Hotel Class & \multicolumn{3}{|c|}{ Ankara } & \multicolumn{2}{|c|}{ Izmir } & \multicolumn{2}{|r|}{$\mathbf{n}$} & \multicolumn{3}{|c|}{$\%$} \\
\hline 5 Star & \multicolumn{3}{|c|}{18} & \multicolumn{2}{|r|}{6} & \multicolumn{2}{|r|}{24} & \multicolumn{3}{|c|}{17.0} \\
\hline 4 Star & \multicolumn{3}{|c|}{33} & \multicolumn{2}{|c|}{25} & \multicolumn{2}{|r|}{58} & \multicolumn{3}{|c|}{41.1} \\
\hline 3 Star & \multicolumn{3}{|c|}{17} & \multicolumn{2}{|c|}{15} & \multicolumn{2}{|r|}{32} & \multicolumn{3}{|c|}{22.7} \\
\hline Boutique & \multicolumn{3}{|c|}{14} & \multicolumn{2}{|c|}{13} & \multicolumn{2}{|r|}{27} & \multicolumn{3}{|c|}{19.1} \\
\hline Total & \multicolumn{3}{|c|}{82} & \multicolumn{2}{|c|}{59} & \multicolumn{2}{|r|}{141} & \multicolumn{3}{|c|}{100.0} \\
\hline \multirow{2}{*}{$\begin{array}{l}\text { Source of } \\
\text { the review }\end{array}$} & \multicolumn{2}{|c|}{ Families } & \multicolumn{2}{|c|}{ Couples } & \multicolumn{2}{|c|}{ Friends } & \multicolumn{2}{|c|}{ Single } & \multicolumn{2}{|c|}{ Business } \\
\hline & $\mathrm{n}$ & $\%$ & $\mathrm{n}$ & $\%$ & $\mathrm{n}$ & $\%$ & $\mathrm{n}$ & $\%$ & $\mathrm{n}$ & $\%$ \\
\hline $5 \mathrm{Star}$ & 5,251 & 35.6 & 10,852 & 28.9 & 3,576 & 27.6 & 8,253 & 26.9 & 14,884 & 32.6 \\
\hline 4 Star & 5,465 & 37.0 & 14,904 & 39.7 & 4,946 & 38.2 & 12,244 & 39.8 & 17,978 & 39.4 \\
\hline 3 Star & 1,729 & 11.7 & 4,631 & 12.3 & 1,923 & 14.9 & 4,555 & 14.8 & 5,264 & 11.5 \\
\hline Boutique & 2,321 & 15.7 & 7,179 & 19.1 & 2,491 & 19.3 & 5,675 & 18.5 & 7,487 & 16.4 \\
\hline Total & 14,766 & 100.0 & 37,566 & 100.0 & 12,936 & 100.0 & 30,727 & 100.0 & 45,613 & 100.0 \\
\hline Grand Total & & 10.4 & & 26.5 & & 9.1 & & 21.7 & & 32.2 \\
\hline
\end{tabular}


The data is collected from both TripAdvisor and Booking for each of these 141 hotels. The data collection process began at January 8, 2017 and finished at March 29, 2017 and so it took about three months. The data collection continuum was endeavored to be finalized as soon as possible because it is known that these sites has a dynamic structure-the content within these channels changes continuously. The variables which are taken into consideration in this research are listed in the Table 2.

Table 2. Variables Collected Within Data Collection Continuum

\begin{tabular}{lcc}
\hline Variable & TripAdvisor & Booking \\
\hline Hotel Class & + & + \\
Number of Rooms & + & + \\
Average Room Rate & + & + \\
Hotel Rank & + & + \\
Total Number of Hotel Reviews & + & + \\
Number of Reviews with Score 1 to 5 & + & + \\
Number of reviews shared by families, couples, groups of & + & + \\
friends, single travelers and business travelers & & + \\
Hotel overall score & + & \\
\hline
\end{tabular}

\subsection{Analysis}

Given the nature of the observed variables, it appears that these data are not suitable for carrying out parametric tests. The type of the collected data is categorical and ordinal. Performing parametric tests requires measurement at interval or ratio level. It is preferred to conduct the non-parametric analysis while testing the hypothesis because parametric test assumptions are not met. While testing the first and the last hypothesis, it is best to perform Wilcoxon signed-rank test in accordance with data and the measurement characteristics which is explained in detail in the results section. On the other hand, the Kruskal-Wallis test is applied to test the second hypothesis. In the remaining hypothesis, the relationships are examined through Spearman's correlation analysis.

\section{Findings}

First, online channels (TripAdvisor and Booking) are examined in terms total number of online reviews for the same hotel. While testing $\mathrm{H}_{1}$ (whether there is a statistically significant difference in total number of hotel reviews between TripAdvisor and Booking or not), Wilcoxon signed-rank test is applied because the hotels are the same and this is a repeated-measure occasion. This non-parametric analysis is applied because the data is ordinal. This test which is also referred as the Wilcoxon matched pairs signed ranks test is used the situations in which there are two sets of scores to compare, but these scores come from the same participants and the non-parametric equivalent of the paired-sample t-test (Field, 2009; Pallant, 2010). The results show that the first hypothesis is accepted and the two sets of scores are significantly different, $\mathrm{z}=$ $-9.901, \mathrm{p}<.001$. The effect size $(\mathrm{r}=.595>.5)$ calculated for this difference can be accepted as large (Cohen, 1988). This analyze reveals that tourists more prefer to share their reviews about hotels located in both Ankara and Izmir whereby one channel than 
another. Most of the tourists share their evaluations about these hotels through Booking rather than TripAdvisor.

In order to check the $\mathrm{H} 2$ (whether there is a statistically significant difference in total number of hotel reviews based on the hotel categories or not) Kruskal-Wallis test is conducted because the dependent variable is ordinal and the independent variable consists of four categorical groups. Kruskal-Wallis test which is sometimes also called as Kruskal-Wallis $\mathrm{H}$ test is the non-parametric alternative to one-way ANOVA (Pallant, 2010; Field, 2009). Test output indicate that null hypothesis is rejected. This test reveals a statistically significant difference in total number of hotel reviews between four hotel classes $\left(x^{2}=23.48,3 d f, P<.05\right)$. It is understood that there is a difference but it is required to apply the post-hoc test in order to go a step further for identifying the source of this difference. Post-hoc tests has revealed that the mean rank score for five star hotels $(M d=104.04)$ is significantly different from the four $(M d=67.49)$, three star $(M d=51.47)$ and the boutique hotels $(M d=72.31)$. Simply it can be said that the fivestar hotel group recorded a higher median score than the other three groups based on the pairwise comparisons. Post-hoc test result is presented in the Figure 1 and Table 3.

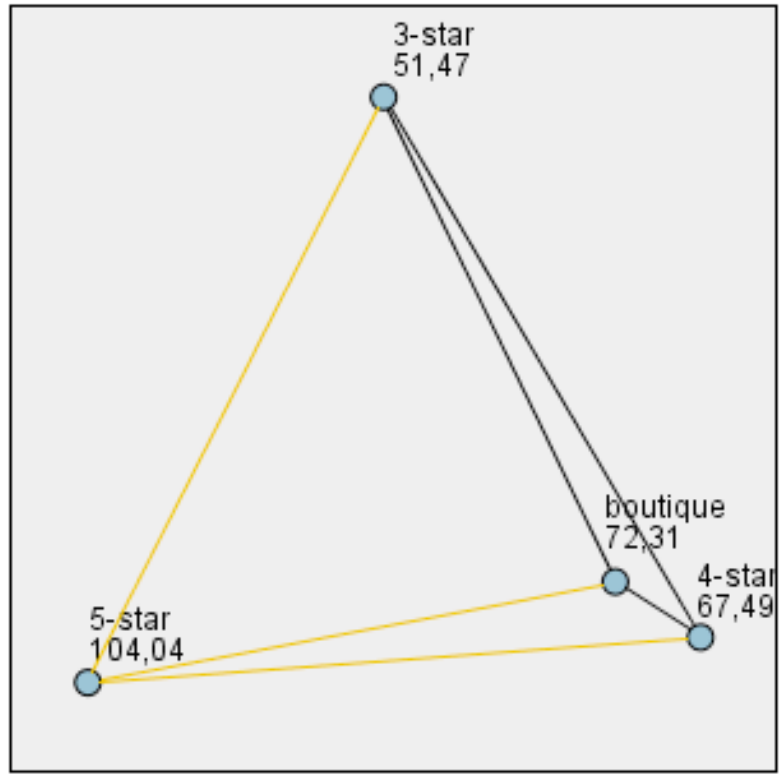

Figure 1. Illustrative Output for Pairwise Comparisons

Table 3. Post-hoc Comparisons

\begin{tabular}{lccccc}
\hline Group Comparisons & $\begin{array}{c}\text { Test } \\
\text { Statistic }\end{array}$ & Std. Error & $\begin{array}{c}\text { Std. Test } \\
\text { Statistic }\end{array}$ & Sig. & Adj. Sig. \\
\hline 3 Star - 5 Star & -52.573 & 11.030 & -4.766 & .000 & $.000^{*}$ \\
4 Star - 5 Star & -36.550 & 9.914 & -3.687 & .000 & $.001^{*}$ \\
Boutique - 5 Star & -31.727 & 11.459 & -2.769 & .006 & $.034^{*}$ \\
3 Star - Boutique & 20.846 & 10.674 & 1.953 & .051 & .305 \\
3 Star - 4 Star & -16.023 & 8.995 & -1.781 & .075 & .449 \\
4 Star - Boutique & 4.823 & 9.516 & .507 & .612 & 1.00 \\
\hline
\end{tabular}

*. The mean rank difference is significant at the 0.05 level. 
The relationship between several variables (average room rates and number of hotel rooms) and total number of hotel reviews is investigated by Spearman's correlation analysis. The result of these analysis takes place in Table 4 and it shows that both $\mathrm{H}_{3}$ and $\mathrm{H}_{4}$ are accepted. There is a positive correlation between total number of hotel reviews and number of hotel rooms, $r=.464, \mathrm{n}=141$ (Table 4). Also, there is a positive correlation between number of hotel reviews and average room rates, $r=.246$, $\mathrm{n}=87$ (Table 4). Although these two relationships are statistically significant, just the first one could be regarded as moderate ( $r$ close to .5$)$ and the second one as low ( $r$ less than .3).

Table 4. Results of Spearman's Correlation Analysis about Number of Hotel Rooms and Average Room Rate Variables

\begin{tabular}{clccc}
\hline & & $\begin{array}{c}\text { Number of } \\
\text { Hotel Rooms }\end{array}$ & $\begin{array}{c}\text { Average } \\
\text { Room Rates }\end{array}$ & $\begin{array}{c}\text { Total Number of } \\
\text { Hotel Review }\end{array}$ \\
\hline $\begin{array}{c}\text { Total Number } \\
\text { of Online Hotel } \\
\text { Review }\end{array}$ & Correlation Coefficient & $.464^{* *}$ & $.246^{* *}$ & 1 \\
Sig. (2-tailed) & $\mathrm{N}$ & .000 & .000 & .000 \\
\hline
\end{tabular}

**. Correlation is significant at the 0.01 level (2-tailed).

Tourists share their hotel experience reviews on TripAdvisor and Booking and they attached a general score related to overall performance of the hotel between 1 to 5 to their reviews. In other words, the online hotel reviews taking place in TripAdvisor and Booking are categorized based on their scores. Thanks to this feature of these sites, it is possible to count total number of reviews for each score groups. In the light of these data, Spearman's correlation analysis is applied to test the relationship between that total number of hotel review and total number of review scored with 1 to 5 (as indicated in the hypothesis 5a to 5e). This correlation analysis results are shown in the Table 5 . As it is expected all the hypothesis starting with 5 are accepted but there is a critical point about their correlation levels. It is found out that total number of hotel review shows the highest level of correlation between number of reviews scored with $5, r=$ $.930, \mathrm{n}=141$ and the lowest level of correlation between number of reviews scored with $1, r=.548$ (Table 5). There is a positive linear trend for these relationships. The level of correlation in these relationships increases linearly from the number of reviews scored with 1 to 5 .

Table 5. Relationship Between Total Number of Hotel Review and Number of Review Based on Their Scores

\begin{tabular}{clccccc}
\hline & & $\begin{array}{c}\text { Review } \\
\text { Score } \\
\mathbf{1}\end{array}$ & $\begin{array}{c}\text { Review } \\
\text { Score } \\
\mathbf{2}\end{array}$ & $\begin{array}{c}\text { Review } \\
\text { Score } \\
\mathbf{3}\end{array}$ & $\begin{array}{c}\text { Review } \\
\text { Score } \\
\mathbf{4}\end{array}$ & $\begin{array}{c}\text { Review } \\
\text { Score } \\
\mathbf{5}\end{array}$ \\
\hline $\begin{array}{c}\text { Total Number } \\
\text { of Online Hotel } \\
\begin{array}{c}\text { Review } \\
\text { Revelation Coefficient }\end{array}\end{array}$ & $\begin{array}{c}.548^{* *} \\
\text { Sig. (2-tailed) }\end{array}$ & $.627^{* *}$ & $.761^{* *}$ & $.863^{* *}$ & $.930^{* *}$ \\
& $\mathrm{~N}$ & .000 & .000 & .000 & .000 & .000 \\
\hline
\end{tabular}

**. Correlation is significant at the 0.01 level (2-tailed).

Most of the review sites make it possible to rank the hospitality enterprises in terms of their success based on the content generated by the tourists. The data which 
represents the hotel success is also available in Booking and TripAdvisor. In this study, the relationship between total number of hotel reviews, ranking and overall score of the hotels in Booking and TripAdvisor separately $\left(\mathrm{H}_{6 \mathrm{a}-6 \mathrm{~d}}\right)$. In order to test these hypothesis, the Spearman's correlation analysis is carried out and three out of four of them are accepted as it can be understood from the Table 6 . The relationship between the total number of hotel review and the overall score is not significant for the Booking data ( $p<$ $.05)$. On the other hand, the same correlation is significant for the TripAdvisor data but it is really low, $r<.3$. Apart from these output, it's clear that there is a negative correlation between the total number of review and ranking of the hotels. While the level of this relationship is lower on Booking $r=.326$, it is higher on TripAdvisor $r=$ .686 .

Table 6. Relationship Between Hotels' Success Indicators and Total Number of Review

\begin{tabular}{llcccc}
\hline & $\begin{array}{c}\text { Booking } \\
\text { Rank }\end{array}$ & $\begin{array}{c}\text { Booking } \\
\text { Overall } \\
\text { Score }\end{array}$ & $\begin{array}{c}\text { TripAdvisor } \\
\text { Rank }\end{array}$ & $\begin{array}{c}\text { TripAdvisor } \\
\text { Overall } \\
\text { Score }\end{array}$ \\
\hline $\begin{array}{c}\text { Total Number } \\
\text { of Online } \\
\text { Hotel Review }\end{array}$ & Correlation Coefficient & $-.326^{* *}$ & .155 & $-.686^{* *}$ & $.288^{* *}$ \\
\hline$* *$ Sig. (2-tailed) & .000 & .076 & .000 & .001 \\
\hline
\end{tabular}

**. Correlation is significant at the 0.01 level (2-tailed).

The last hypothesis is about the hotels' ranking difference between two sites. $\mathrm{H}_{7}$ (whether there is a statistically significant difference in ranking of the hotels between TripAdvisor and Booking or not) is tested by Wilcoxon signed-rank test The results show that this hypothesis is accepted and the two lists of hotel ranking orders are significantly different, $\mathrm{z}=-4.926, \mathrm{p}<.001$. The effect size $(\mathrm{r}=.32>.3)$ calculated for this difference can be accepted as medium (Cohen, 1988). This analyze reveals that ranking of the hotels are statistically different in these two sites. Most of the hotels' $(62,4 \%$ of the observation) ranking in Booking is higher than their ranking in TripAdvisor.

\section{Conclusion and Discussion}

First, it is uncovered that most of the online reviews about urban hotels located in Ankara and Izmir are shared on Booking (OTAs) rather than TripAdvisor (social media sites/virtual community). Xiang and Gretzel (2010) have found out that the most popular website types in the tourism domain are the social media sites like virtual communities and review platforms. Although the social media channels are the most common websites type when a search is done on tourism related issues in the search engines, OTA sites come into prominence when the online hotel reviews are a matter of. That's why hotel management have to focus on both of these sites and especially on the OTAs. It is obvious that Booking gets the lion's share of this cake. On the other hand, number of reviews are not evenly distributed among the different categories of hotels. As $\mathrm{H}_{2}$ is accepted within this study, there is a statistically significant difference in total number of hotel reviews among the four hotel classes. Number of 5-star hotel reviews is significantly higher than the number of other hotel classes reviews. This result can be interpreted that big scale hotels are reviewed by their customers more than the small and mid-scale hotels. This result can be corroborated with the result of another analysis. 
Acceptance of $\mathrm{H}_{3}$ is a supporting result for the previous one. As the number of hotel room increases, the total number of review is increases in the same trend with a medium-level correlation. Of course, interpreting this statistical results can be regarded as a limited approach. If the hotels' occupancy rates are considered together with the number of hotel rooms, healthier results will be obtained. From this point of view, absence of the data related with the occupancy of these hotels is considered to be the limitation of this study. When the number of hotel room results are evaluated together with the hotel class results, it is possible to say that bigger hotels have advantageous or disadvantageous to be reviewed more than the other hotels. This may be explained by the profile of big hotels' customers or their high number of customers. The cause of it could be another research question for future researches.

In this research, the relationship between the total number of online reviews and average room rates is examined. It has been shown that there is a low positive relationship between average room rate and total number of online hotel reviews. That is to say, the number of online hotel reviews will increase as long as the average room rates increase. This research result is consistent with the result of Yoo and Gretzel's (2012) study. They showed that tourists who have higher income, have higher tendency to share online hotel reviews. There is an interesting point which is uncovered by this study. There is a positive linear trend for total number of online hotel reviews in accordance with the number of reviews scored 5 to 1 . In other words, this research has revealed that when total number of hotel review increases the number of reviews scored with 5 will be higher than scored with 1 . This result can be supported by research results of Öğüt and Cezar (2012) and Melián-González et al. (2013). They revealed that tourists' propensity to write positive reviews is higher than the writing negative reviews. Also, Gretzel and Yoo (2008) have underlined that travel review writers are mostly motivated by intrinsic motives of enjoyment, concerns for other travelers or the desire to help the company while only some are motivated by the opportunity for venting. Consequently, hotel managements shouldn't be afraid of to be reviewed. There could be negative reviews for sure but these give hotel managements chances to recover their service failures. As Chan and Guillet (2011) stated that these channels are not only online distribution channel, but also as an effective tool to perform service recovery, develop relationship with customers and build loyalty. On the other hand, the relationship between the total number of hotel review and the overall score is evaluated in the sixth hypothesis and the results of it show that the relationship is not significant (in Booking) or significant in very low level (in TripAdvisor). These results denote that more reviews do not mean higher scores for hotels. The results of hypothesis five and six cannot be found conflicting. When these two results considered together, simply it is possible to say that hotel managements shouldn't be worried about higher number of reviews but more reviews don't always bring higher scores. Average scores and the ranking of the hotels in the review sites, are calculated with a complex algorithmic method. The only criterion is not the total number of online reviews. For example, as the reviews become dated, their effect on hotel overall scores will be decreasing while current reviews, scores affect hotels overall scores and rankings more as it is explained in these sites. In the last hypothesis, the consistency of the hotels' ranking in two sites is investigated. It is understood that ranking of the hotels are statistically different in these two sites. Generally, hotels' ranking in Booking is higher than their ranking in TripAdvisor. Hotel managements strive to get better reviews and scores from the tourists who have TripAdvisor accounts in order to have a better ranking in 
TripAdvisor. Hotels who have consistent and higher ranking scores in these two sites will get advantageous to be successful.

The result of this study contributes practically to hotel managements and theoretically to the literature. Industry practitioners may make use of the result of this research in terms of the management of review sites. First of all, they can change their attitudes because there is no need to worry about the negative online hotel reviews. If the negative review number is kept in low level, its effect will be minimized. Apart from this, it is obvious that big scale hotels are more successful than the others. Small and mid-scale hotels may apply to benchmark with the successful hotels so as to have a better virtual image. The scientific information about the online review sites is available and hotels can develop strategies related with these sites in healthier manner. On the other hand, there is still lack of empirical research related with this issue. The data is consisting of the hotels located in Ankara and Izmir in this research. In the future research studies, the data can be collected from different urban tourism destinations in different countries. Also, Researchers can investigate the similar things with this research based on different hotels (thermal, mountain, resort hotels etc.). Thus, it is possible to make comparison between these hotel types. Furthermore, different variables related with these review sites can be identified as well.

\section{References}

Bansal, H.S. and Voyer, P.A. (2000). Word-of-mouth Processes within a Services Purchase Decision Context. Journal of Service Research, 3 (2), 166-177.

Bickart, B. and Schindler, R. M. (2001). Internet Forums as Influential Sources of Consumer Information. Journal of Interactive Marketing, 15 (3), 31-40.

Bronner F. and Hoog, D. R. (2011). Vacationers and e-WOM. Who posts, and Why, Where, and What? Journal of Travel Research, 50 (1), 15-26.

Buhalis, D. and Law, R. (2008). Progress in Information Technology and Tourism Management: 20 Years on and 10 Years after the Internet-The state of eTourism Research. Tourism Management, 29, 609-623.

Cantallops, A. S. and Salvi, F. (2014). New Consumer Behavior: A Review of Research on eWom and Hotels. International Journal of Hospitality Management, 36, 41-51.

Chan, N. L. and Guillet, B. D. (2011). Investigation of Social Media Marketing: How Does the Hotel Industry in Hong Kong Perform in Marketing on Social Media Websites? Journal of Travel and Tourism Marketing, 28 (4), 345-368.

Chatterjee, P. (2001). Online Reviews: Do Consumers Use Them? In M.C. Gilly and J. Myers-Levy (Eds.), Proceedings of the ACR 2001 (pp. 129-134). Provo, UT: Association for Consumer Research.

Chung, J. Y. and Buhalis, D. (2008). Web 2.0: A Study of Online Travel Community. O'Connor, P., Höpken, W., Gretzel, U. (Eds.), Information and Communication Technologies in Tourism 2008 (pp. 70-81). Springer, Vienna, Austria.

Cohen, J. (1988). Statistical Power Analysis for the Behavioral Sciences (2 ${ }^{\text {nd }}$ Edition). Hillsdale, NJ: Lawrence Erlbaum Associates. 
Field, A. P. (2009). Discovering Statistics Using SPSS: and sex and drugs and Rock'n'roll ( $3^{\text {rd }}$ Edition). London: SAGE Publications.

Filieri, R. and McLeay, F. (2013). E-Wom and Accommodation: An Analysis of the Factor That Influence Travelers' Adoption of Information from Online Reviews. Journal of Travel Research, 53 (1), 44-57.

Gretzel, U., and Yoo, U. (2008). Use and Impact of Online Travel Reviews. O'Connor, P., Höpken, W., Gretzel, U. (Eds.), Information and Communication Technologies in Tourism 2008 (pp. 35-46). Springer, Vienna, Austria.

Jeong, M. and Jeon, M. M. (2008). Customer Reviews of Hotel Experiences through Consumer Generated Media (CGM). Journal of Hospitality and Leisure Marketing, 17 (1-2), 121-138.

Kaplan, A. M., and Haenlein, M. (2010). Users of the World, Unite! The Challenges and Opportunities of Social Media. Business Horizon, 53, 59-68.

Leung, D., Law, R., Hoof, H.V., and Buhalis, D. (2013). Social Media in Tourism and Hospitality: A Literature Review. Journal of Travel and Tourism Marketing, 30, $3-22$.

Litvin, S. W., Goldsmith, R. E. and Pan, B. (2008). Electronic Word-of-Mouth in Hospitality and Tourism Management. Tourism Management, 29, 458-468.

Litvin, S. W. and Hoffman, L. M. (2012). Responses to Consumer-Generated Media in the Hospitality Marketplace: An Empirical Study. Journal of Vacation Marketing, 18(2), 135-145.

Liu, S., Law, R., Rong, J., Li, G. and Hall, J. (2013). Analyzing Changes in Hotel Customers' Expectations by Trip Mode. International Journal of Hospitality Management, 34, 359-371.

Melián-González, S., Bulchand-Gidumal, J., and López-Valcárcel, B. G. (2013). Online Customer Reviews of Hotels: As Participation Increases, Better Evaluation Is Obtained. Cornell Hospitality Quarterly, 54 (3), 274-283.

Munzel, A. and Kunz, W. H. (2014). Creators, Multipliers, and Lurkers: Who Contributes and Who Benefits at Online Review Sites. Journal of Service Marketing, 25 (1), 49-74.

O'Connor, P. (2010). Managing a Hotel's Image on TripAdvisor, Journal of Hospitality Marketing and Management, 19 (7), 754-772.

Öğüt, H. and Cezar, A. (2012). The Factors Affecting Writing Reviews in Hotel Websites. $8^{\text {th }}$ International Strategic Management Conference.

Pallant, J. (2010). SPSS Survival Manual: A Step by Step Guide to Data Analysis Using $\operatorname{SPSS}\left(4^{\text {th }}\right.$ Ed.). Maidenhead: Open University Press/McGraw-Hill.

Park, D.H., Kim, S. and Han, J. (2007). The Effects of Consumer Knowledge on Message Processing of Electronic Word of Mouth Via Online Consumer Reviews. ECIS 2007, St. Gallen, Switzerland.

PhoCusWright (2008). The PhoCusWright Consumer Travel Trends Survey Tenth Edition. Date of Access: 07.06.2015, Retrieved from: www.phocuswrights.com 
Schuckert, M., Liu, X. and Law, R. (2015). Hospitality and Tourism Online Reviews: Recent Trends and Future Directions. Journal of Travel and Tourism Marketing. $32(5), 608-621$.

Statisticbrain, (2014). Internet Travel Hotel Booking Statistics. Date of Access: 01.05.2016, Retrieved from: http://www.statisticbrain.com/internet-travel-hotelbooking-statistics/

Stringam, B. B. and Gerdes, J. (2010). An Analysis of Word-of-Mouse Ratings and Guest Comments of Online Hotel Distribution Sites. Journal of Hospitality Marketing and Management, 19 (7), 773-796.

Xiang, Z. and Gretzel, U. (2010). Role of Social Media in Online Travel Information Search. Tourism Management, 31, 179-188.

Xie, K. L., Chen, C., and Wu, S. (2016). Online Consumer Review Factors Affecting Offline Hotel Popularity: Evidence from Tripadvisor, Journal of Travel and Tourism Marketing, 33 (2), 211-223.

Xie, K. L., Zhang, Z., and Zhang, Z. (2014). The Business Value of Online Consumer Reviews and Management Response to Hotel Performance. International Journal of HospitalityManagement, 43, 1-12.

Yacouel, N. and Fleischer, A. (2012). The Role of Cybermediaries in Reputation Building and Price Premiums in the Online Hotel Market. Journal of Travel Research, 51 (2), 219-226.

Yoo, K. and Gretzel, U. (2012). Use and Creation of Social Media by Travellers. Sigala, M., Christou, E. and Gretzel, U. (Eds.), Social Media in Travel, Tourism and Hospitality: Theory, Practice and Cases (pp. 189-205). United Kingdom: Ashgate. 